\title{
Editorial
}

\section{Editorial from the Academic Editor: Future directions}

Place Branding and Public Diplomacy (2010) 6, 182. doi:10.1057/pb.2010.23

As the recently appointed Academic Editor of Place Branding and Public Diplomacy, this may be an opportune time to reflect on the future direction and development of the journal. Since its inception in 2004, the journal has quickly established itself as a vibrant forum for the dissemination of both academic and practitioner articles on a wide range of issues related to the impact of branding and diplomatic practice upon national, regional and civic development. Under the guidance of Place Branding and Public Diplomacy's Founder and Managing Editor, Simon Anholt, the journal will continue to play its groundbreaking role in reaching out to a far more diverse and heterogeneous audience than other more narrowly focused single-discipline journals.

During the coming years, at Place

Branding and Public Diplomacy we intend to further strengthen the essentially interdisciplinary nature of the journal. This will be achieved through encouraging an increase in the submission of papers that emanate from disciplines such as international relations, political science, development studies and so on. These disciplines are crucial to developing knowledge and understanding of the context and nature of place branding and public diplomacy, yet they remain severely under-represented in the steadily growing body of place branding literature.

In addition to extending the interdisciplinary aspect of the journal, we also aim to broaden the geographic coverage of the articles published in the journal. This will be done not only in terms of the spectrum of countries, regions and cities as the focus of study of submitted papers but also in terms of the geographic dispersal of contributing authors. To this end, four Regional Editors have been appointed in order to stimulate the submission of papers to the journal from as wide a geographic spread as possible. The role of the Regional Editors is also to help raise the profile of the journal among regional audiences; assist in the recruitment of suitably qualified reviewers to enhance the efficiency of the journal's review process; and to participate in the process of identifying interesting and relevant themes for occasional special issues of the journal. The Regional Editors appointed to help the journal achieve these goals are as follows: Dr Edgar Centeno (the Americas and the Caribbean), Dr João Freire (Europe, Middle East and Africa), Dr Andrea Insch (Australia and New Zealand) and Dr You-kyung Kim (Asia). Further details about the Regional Editors can be found on the journal's web page.

With this new team of Editors in place, we look forward to an exciting new phase in developing the impact and reputation of the journal across its broad and interdisciplinary set of audiences.

Keith Dinnie Temple University, Japan Campus, Tokyo, Japan E-mail:dinnie@tuj.ac.jp 